\title{
OP-0186-Efficacy Of Platelet Rich Plasma Injection In Diabetic Neuropathy: Double Blinded Randomized Controlled Trial
}

\section{Walaa A. Khalifa 1. Manal M. Hassanien 2, Abdel-Rahem Al-awamy3, Yasmin S. Hussein 2, Heba M Abdellhafez ${ }^{4}$}

1-Endocrinology unit, Internal medicine department, , faculty of medicine, Assuit university, Egypt

2-Rheumatology and Rehabilitation department, , faculty of medicine, Assuit university, Egypt.

3- Anesthesia department, faculty of medicine, Assuit university, Egypt.

4- Clinical pathology department, faculty of medicine, Assuit university, Egypt.

Background:Neuropathy is a common complication of diabetes mellitus (DM) with a wide clinical spectrum. Till now there is no available effective therapy for the treatment of diabetic peripheral neuropathy (DPN). Autologous platelet-rich plasma is easy and cost-effective method as it provides necessary growth factors that promote angiogenesis and axon regeneration .

Objective: To evaluate the clinical efficacy and safety of peri-neural injection of platelet rich plasma (PRP) in the treatment of diabetic peripheral neuropathy compared to traditional medical treatment.

Method : Prospective double blinded randomized controlled trial was conducted (ClinicalTrials.gov Identifier: NCT03250403) . All included patients had type 2 DM selected from Endocrinology unit Department of Internal medicine, Assuit university Hospital, Egypt . DPN of at least 5 years duration of symptoms. Patients with other causes of neuropathy like hereditary neuropathies, entrapment neuropathies , overt neuropathy with foot ulcers and /or amputation, peripheral arterial disease ,connective tissue diseases, vertebral diseases ,thyroid disorders and end organ failure were excluded . Neuropathy was assessed by the modified Toronto Clinical Neuropathy Score (mTCNS) $2009^{3}$.

\begin{tabular}{|c|c|}
\hline Symptom scores & Sensory test scores \\
\hline Foot pain & Pinprick \\
\hline Numbness & Temperature \\
\hline Tingling & Light touch \\
\hline Weakness & Vibration \\
\hline Ataxia & Position Sense \\
\hline \multicolumn{2}{|l|}{ Upper limb symptoms } \\
\hline Symptom scores graded as & Sensory test scores graded as \\
\hline $0=a b s e n t$ & $0=$ normal \\
\hline $\begin{array}{l}1 \text { = present but no interference with sense } \\
\text { of well-being or activities of daily living }\end{array}$ & $1=$ reduced at the toes only \\
\hline $\begin{array}{l}2=\text { present, interferes with sense of well- } \\
\text { being but not with activities of daily living }\end{array}$ & $\begin{array}{l}2=\text { reduced to a level above the toes, but } \\
\text { only up to the ankles }\end{array}$ \\
\hline $\begin{array}{l}3=\text { present and interferes with both sense } \\
\text { of well-being and activities of daily living } \\
\text { (both) }\end{array}$ & $\begin{array}{l}3=\text { reduced to a level above the ankles } \\
\text { and/or absent at the toes }\end{array}$ \\
\hline
\end{tabular}

Baseline pain and nerve conduction studies were done. Regardless of age and gender participants were double blindly divided into two groups. Group I who underwent PRP peri-neural injection under ultrasound guidance plus medical treatment and group II who received primary medical treatment (vitamin B complex,$\alpha$ lipoic acid, SSRI) only. Blood glucose was strictly controlled in both groups. Patients were followed at 1,3and 6 months by mTCNS and by nerve conduction studies.
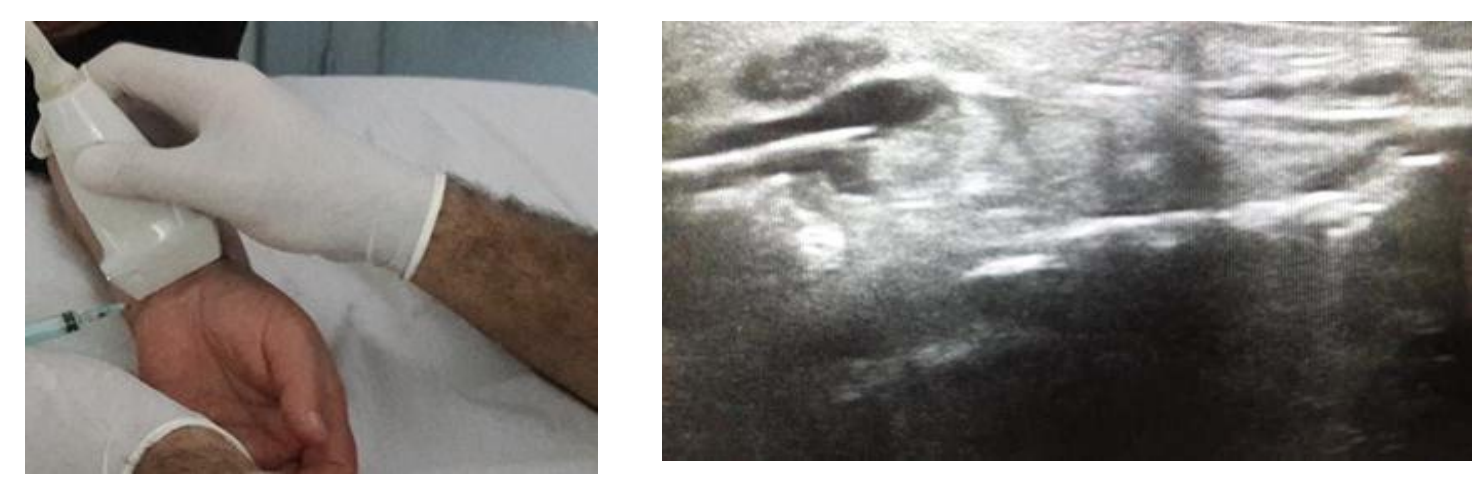

References

1. Tesfaye S, Boulton AJ, Dyck PJ, Freeman R, et al. Diabetic neuropathies: update on definitions, estimation of severity, and treatments. Diabetes Care 2010; 33:2285-2293

2. Bhanot S, Alex JC. Current applications of platelet gels in facial plastic surgery. Facial Plast Surg.2002;18:27-33

3. V Bril, S Tomioka,* R A Buchanan,Perkins BA. Reliability and validity of the modified Toronto Clinical Neuropathy Score in diabetic sensorimotor polyneuropathy. Diabet Med. 2009 Mar; 26(3): $240-246$
Results: the study included 60 patients with type 2 DM and DPN . 40 patients underwent PRP peri-neural injection. 33(55\%) were females with a mean age $35.27 \pm 12.86$ years with duration of DPN $7.42 \pm 1.51$ years . Nerve conduction study showed axonal affection in only $16 / 60$ cases (26\%) and $100 \%$ had delayed distal motor latency (DML) and prolonged motor conduction velocities (NCV).

Figure(1):Patient satisfaction was significantly better in PRP group compared to control group till 6 month follow up.

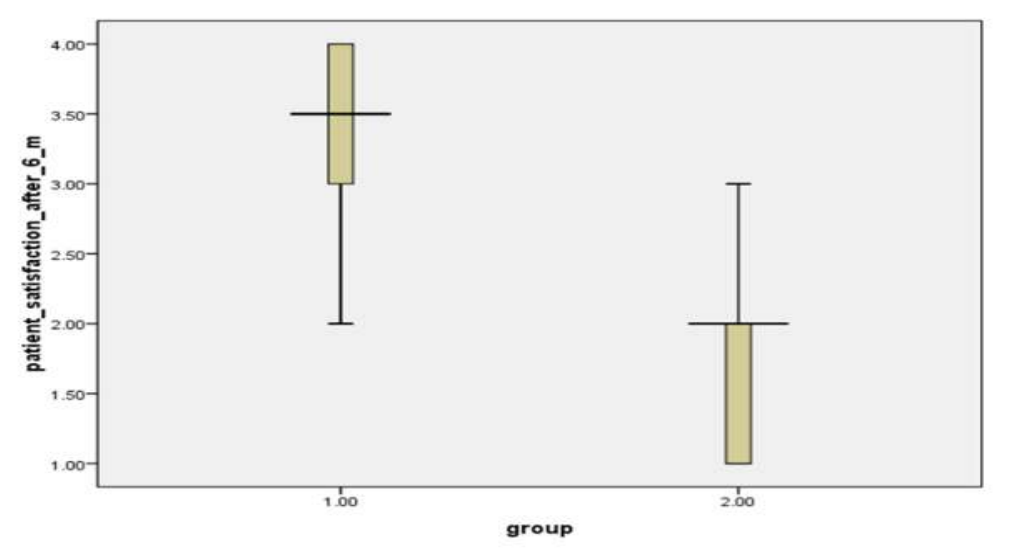

Table (1): Relation of primary outcome variables in both groups

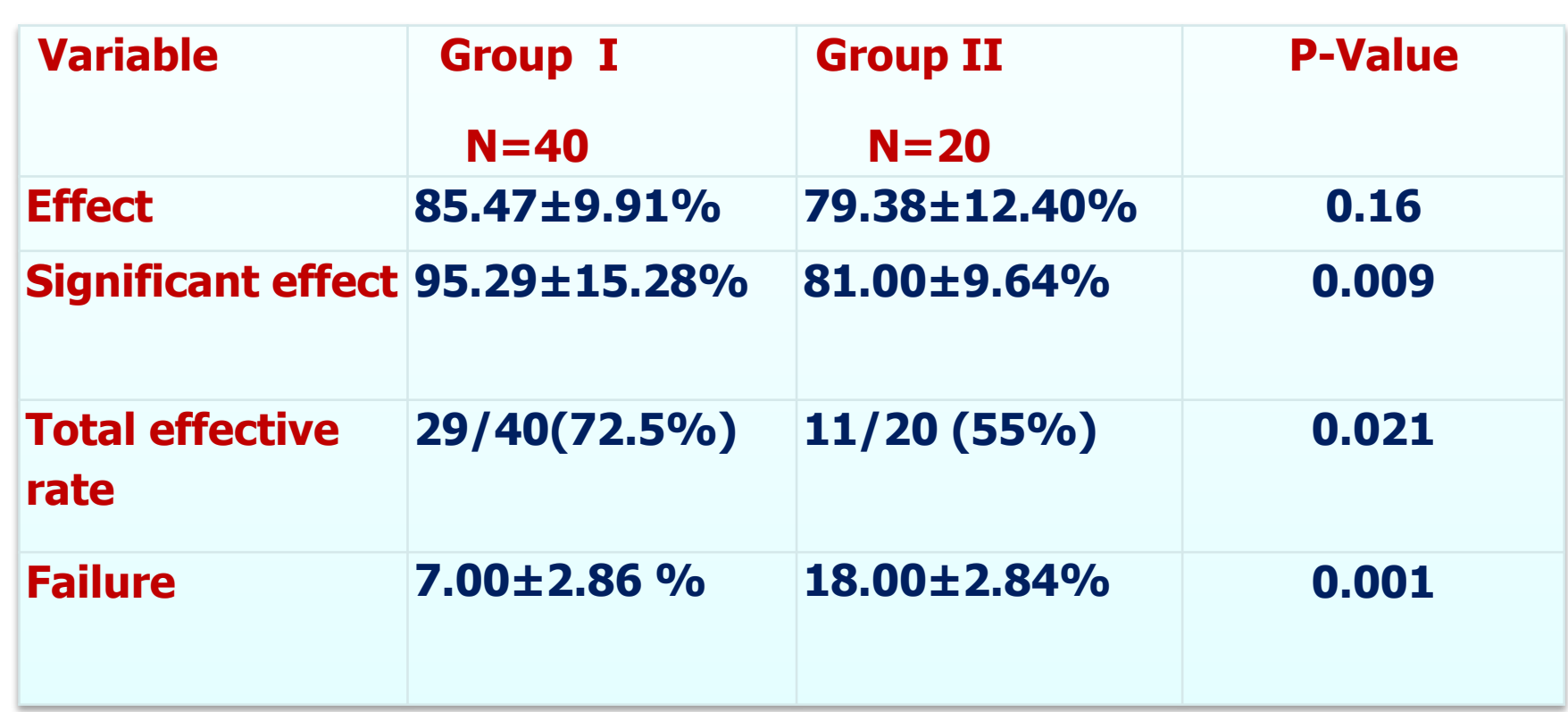

Table (2) : The changes of outcome variables from baseline to 6 month between group I and group II.

\begin{tabular}{|l|c|c|c|}
\hline & $\begin{array}{l}\text { Group I } \\
\text { Variable }\end{array}$ & $\begin{array}{l}\text { Group II } \\
\text { N=20 }\end{array}$ & P-value \\
\hline Patient satisfaction (\%) & $39.9 \pm 3.4$ & $5.1 \pm 3.2$ & $\leq 0.001 *$ \\
\hline mTCNS & $-10.7 \pm 2.3$ & $-3.3 \pm 1.1$ & $\leq 0.001 *$ \\
\hline $\begin{array}{l}\text { Mean motor NCV (UL) } \\
\text { (m/s) }\end{array}$ & $6.78 \pm 3.1$ & $2.96 \pm 1.2$ & $0.006 *$ \\
\hline $\begin{array}{l}\text { Mean motor NCV (LL) } \\
\text { (m/s) }\end{array}$ & $7.2 \pm 1.6$ & $4.3 \pm 1.5$ & $\leq 0.05$ \\
\hline DML (UL) (ms) & $-0.3 \pm 0.1$ & $-0.4 \pm 0.2$ & 0.42 \\
\hline DML (LL) (ms) & $-0.4 \pm 0.2$ & $-0.28 \pm 0.07$ & 0.15 \\
\hline $\begin{array}{l}\text { Sural conduction } \\
\text { velocity(m/s) }\end{array}$ & $12.18 \pm 5.2$ & $2.44 \pm 1.02$ & $\leq 0.001 *$ \\
\hline
\end{tabular}

\section{Conclusion}

Application of PRP peri-neural injection is an effective and safe adjunct therapy in cases of diabetic DPN. Both clinical and nerve conduction parameters were improved .Also it significantly improve neuropathic symptoms. Wide scale studies are recommended as only few small reports with short follow-up period have shown clinical benefits of (PRP) application in P N. 